\title{
APPLICATION OF INCREMENTAL SHEET FORMING
}

\author{
Krzysztof Karbowski \\ Cracow University of Technology, Institute of Production Engineering, Poland \\ Corresponding author: \\ Krzysztof Karbowski \\ Cracow University of Technology \\ Institute of Production Engineering \\ Al. Jana Pawła II 37, 31-864 Kraków, Poland \\ phone: (+48) 12 628-32-47 \\ e-mail:karbowski@mech.pk.edu.pl
}

Received: 3 September 2015

Accepted: 14 September 2015

ABSTRACT

This paper describes some manufacturing aspects and an example of application of the Incremental Sheet Forming (ISF) technology which was used for production of the craniofacial prosthesis. The brief description of prosthesis designing was presented as well. The main topic of the paper is comparison of milling and ISF technologies for preparing the tools for prosthesis thermoforming.

KEYWORDS

sheet forming, milling centre, prosthesis.

\section{Introduction}

The name "Incremental Sheet Forming (ISF)" is used for a variety of processes, all characterized by the fact that at any time only a small part of the product is actually formed, and that the area of local deformation is moving around the entire product [1] (Fig. 1).

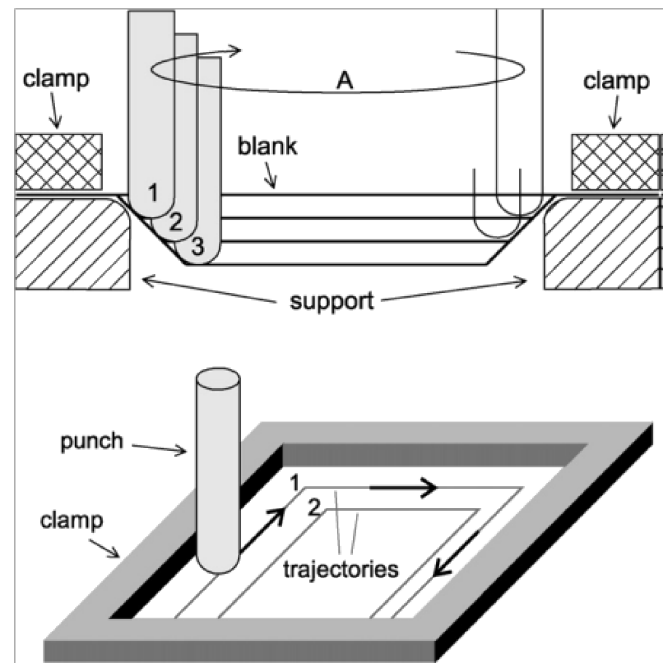

Fig. 1. Principles of ISF process [1].
The ISF process has been described in scientific and technical literature. Park and Kim [2] have demonstrated results of investigation for production of aluminium sheet components. They draw attention to difficulties to form sharp corners and showed the results of stretching and strain distribution simulations.

However Kopac and Kampus [3] showed the ISF process, realized on CNC-milling center and they described technological aspects of the process.

On the other hand Araghi et al. [4] proposeed the hybrid technique - incremental sheet forming combined with stretch forming.

Kim and Yang [5] analysed the geometrical and mechanical aspects of incremental sheet forming process.

Similar aspects have been described by Shim and Park [6].

ISF application for customised medical products was described by Ambrogio et al. [7] and forces analysis during ISF process was presented in article [8].

\section{Incremental sheet forming}

The presented article describes one of the variants of ISF process - Single Point ISF. The process schema illustrates Fig. 2. 

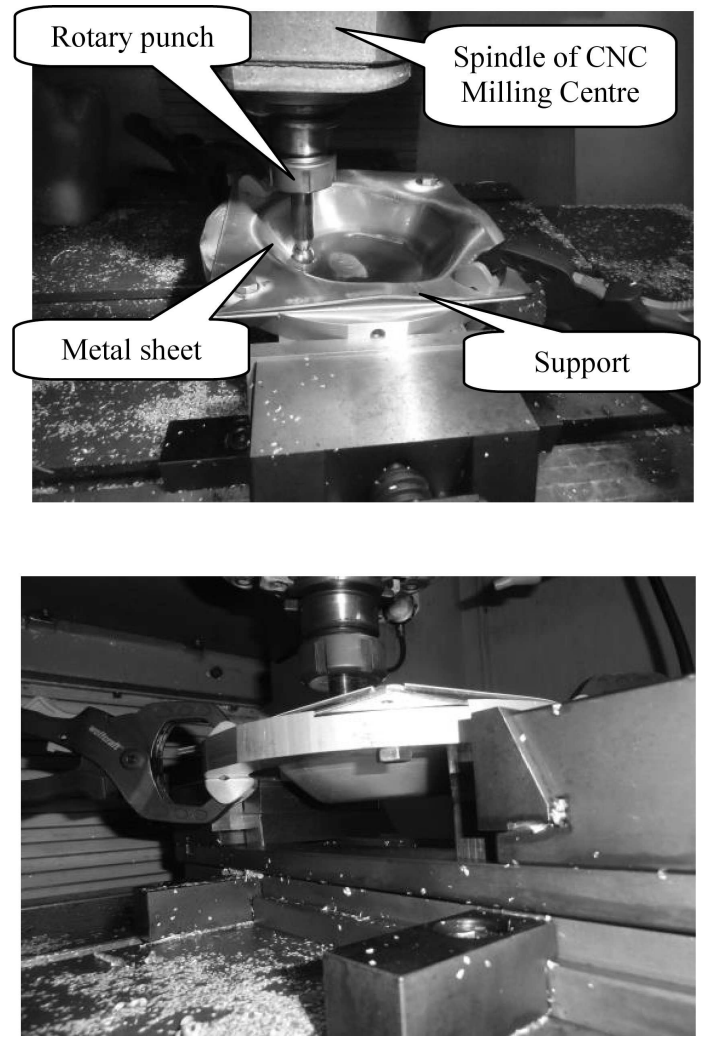

Fig. 2. Process schema.

The process is realized on CNC milling centre and is similar to $Z$-level milling process (the tool goes through trajectories, which are equidistant of the final product in parallel sections in $Z$-axis). The punch tool is mounted in the spindle and rotates for minimizing of the tool slide and the tool abrasive wear. The sheet plate is mounted on the support (Fig. 3), which has the shape of the top of final product.

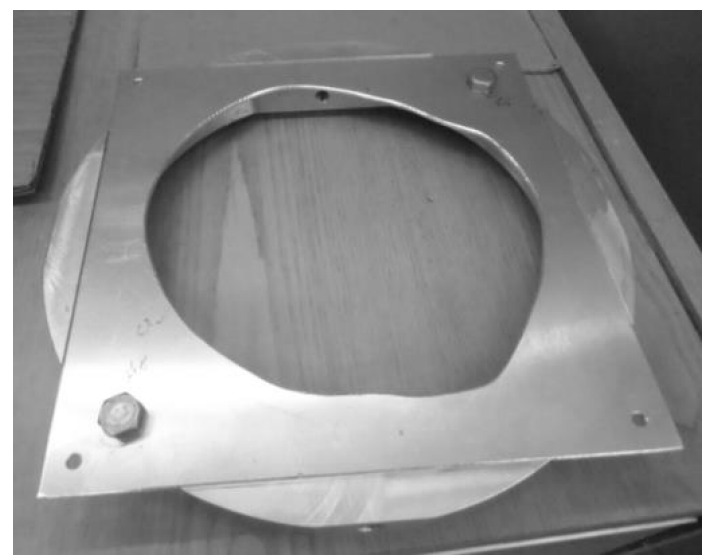

Fig. 3. Support for ISF process.

The ball punch tool was made of steel NC6. The 3 types of punch tools of various diameters have been tested: $10 \mathrm{~mm}, 13 \mathrm{~mm}, 17 \mathrm{~mm}$. The distance be- tween passes in Z-axis was variable in a range of 0.1$0.3 \mathrm{~mm}$. The distance value has been calculated using Computer Aided Manufacturing (CAM) software (CATIA - Advanced Machining Module) assuming the maximum scallop height $0.02 \mathrm{~mm}$. The fixed oil has been used as lubricant. Following machining parameters have been applied: feed rate $1700 \mathrm{~mm} / \mathrm{min}$; tool rotation 40-60 rev./min depending on tool diameter for minimizing the tool slide.

The results of ISF process realized by the punch tools of diameter $10 \mathrm{~mm}$ and $13 \mathrm{~mm}$ are shown at Fig. 4.

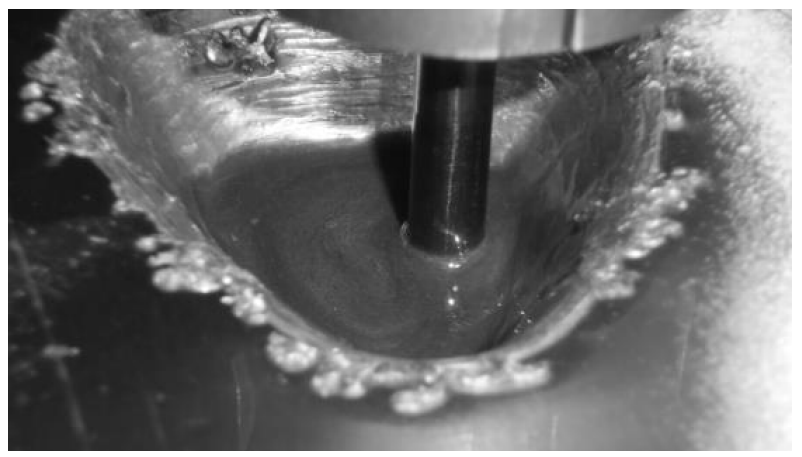

Fig. 4. Skinning during ISF process.

The high unit pressure caused skinning of the stock.

The three components of machining force have been measured during process realized by the punch of diameter $17 \mathrm{~mm}$ (dynamometer type 9257B and amplifier type 5019A made by Kistler). The maximum values of $F_{x}$ and $F_{y}$ forces achieved $250 \mathrm{~N}$; maximum value of $F_{z}$ achieved $500 \mathrm{~N}$ respectively, where $Z$-axis was parallel to tool's axis.

Next the designed and manufactured shapes have been compared (Fig. 5).

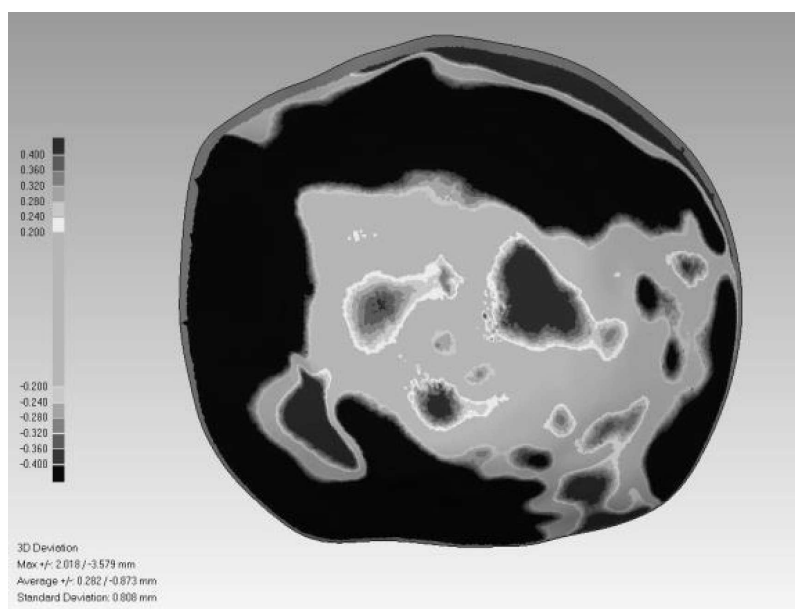

Fig. 5. Deviations between designed and manufactured shapes. 
Based on deviations analysis two main conclusions can be formulated (Fig. 6):

- reverse curvature (Fig. 6) - the metal sheet is formed as free-form shape without die block. It increases the shape's errors;

- steep walls (Fig. 6) - the variation of sheet thickness due forming increases the shape's errors as well.

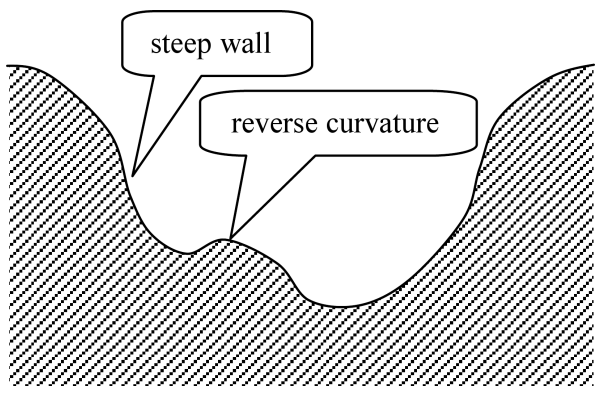

Fig. 6. Designed shape's influence on process realization.

Described problems determined change of the sheet forming method.

The incremental sheet forming has been evolved to mould-incremental sheet forming (Fig. 7). The die-block can be a support for sheet plate in reverse curvature areas. The modified process is similar to traditional sheet forming with die-block, but without complicated press tool. It gives a chance to decrease costs, because universal ball punch tool can be used instead of a complicated shape tool.

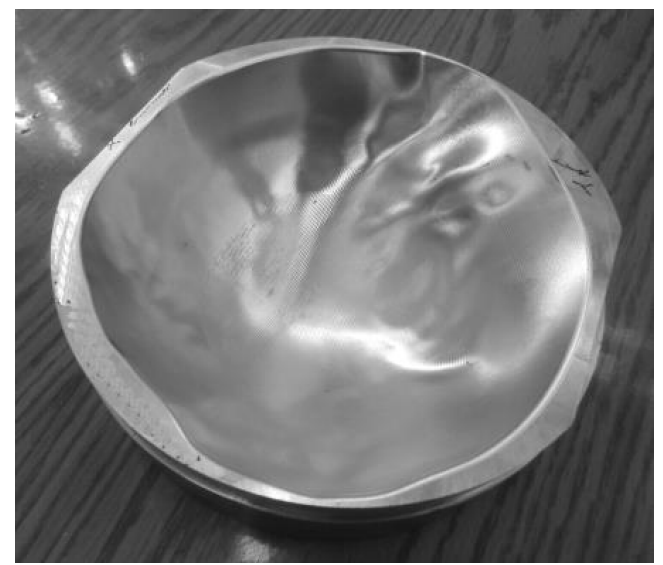

Fig. 7. Die-block for mould-incremental sheet forming.

Special software has been elaborated in order to minimize shape's error on steep wall.

The sheet thickness can be calculated based on relation between local area of plate $\left(P_{p}\right)$ and local area of final product $\left(P_{s}\right)$ - the area ratio $(r)$ has been defined as (Fig. 8):

$$
r=\frac{P_{p}}{P_{s}}
$$

The convenient format for describing geometry in above situation is STL (STereoLithography [9]). The geometry is defined by triangles (Fig. 8), which can be used for calculating the area ratio (1). Therefore the final local thickness $\left(a_{s}\right)$ is calculated as:

$$
a_{s}=r \cdot a_{p},
$$

where $a_{p}$ is the thickness of semi-finished plate.

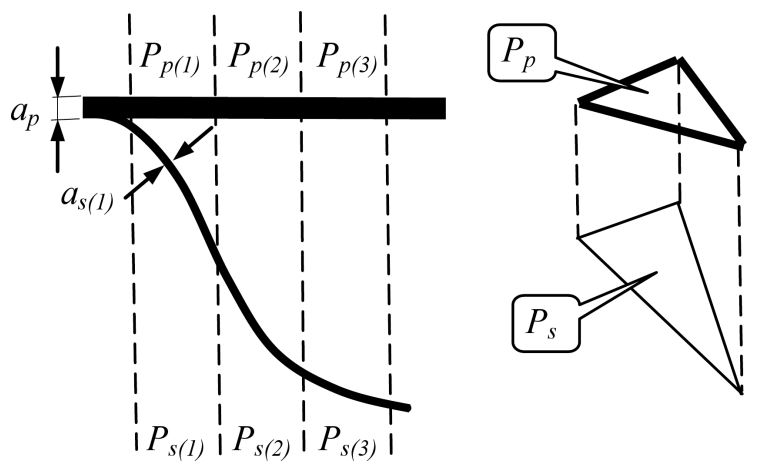

Fig. 8. Area ratio.

The software calculates the final thickness (thickness of a final product) and generates the STL file which contains the geometry of equidistant surface, which is a base for die-block surface. Subsequently the generated surface is the base for preparing the machining program for the 3 -axis milling centre.

The modified ISF process has been implemented for preparing new element. As a result shape errors have been decreased (Fig. 9).

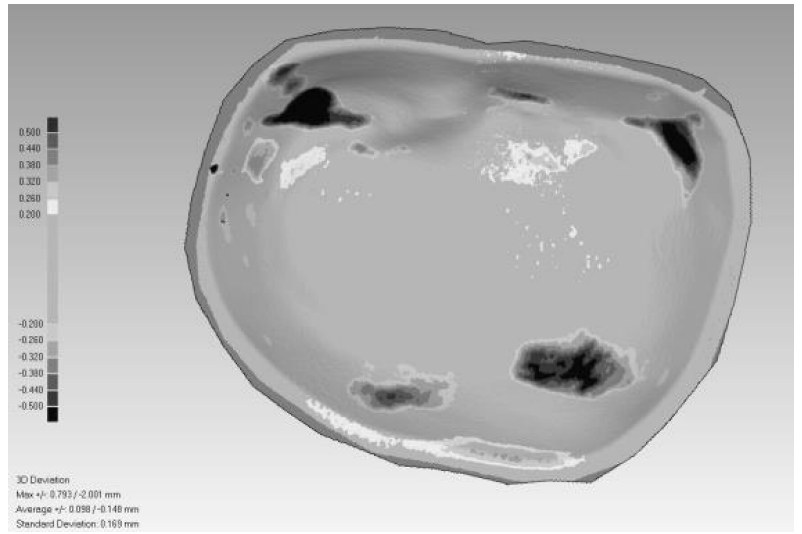

Fig. 9. Shape errors after modification of ISF process. 


\section{Application}

The described mould incremental sheet forming process has been used for making the skull prosthesis (Fig. 10).

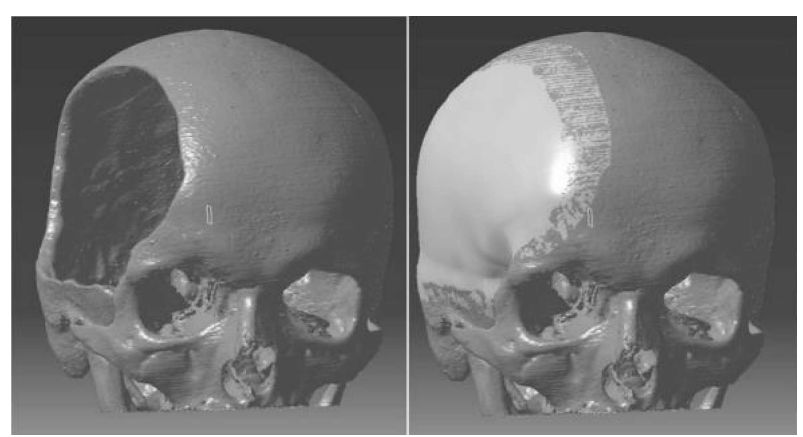

Fig. 10. Skull hole and hole filling.

The skull hole was a result of craniectomy surgery. The virtual skull model has been prepared, based on the analysis of computed tomography images [10].

The prosthesis was produced by medical materials company using polypropylene and polyester knitted yarn, which was next thermoformed [11].

The base for prosthesis thermoforming was the form, which was designed based on the virtual model of the skull [12] (Fig. 11).

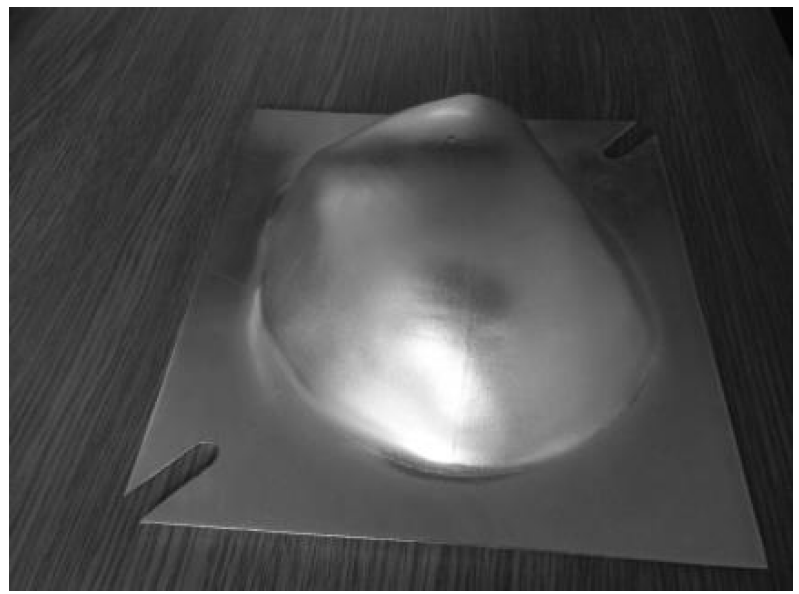

Fig. 11. Prosthesis form.

The form has been manufactured using mould incremental sheet forming process.

The thermoformed prosthesis has been implanted during cranioplasty surgery (Fig. 12).

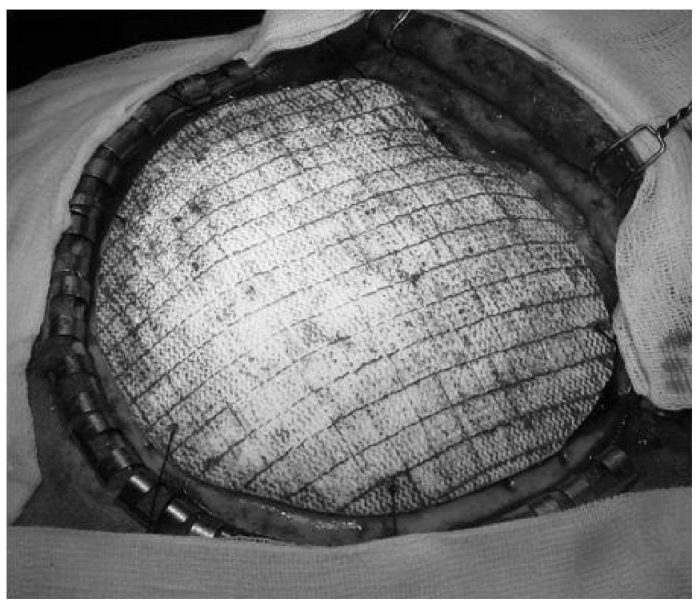

Fig. 12. Implanted prosthesis.

\section{Conclusions}

The described mould incremental sheet forming process gives a chance for preparing free-form shapes in the piece or short-run production. The process requires die-block, but the complicated and expensive press tool is replaced by universal ball punch.

The developed software can be used for calculation sheet thickness after forming, however the mould enables forming the sheet with convex and concave (reverse curvature) shapes.

The mould incremental sheet forming process has been used successfully for preparing skull bone prosthesis, which has been implanted to the patient during cranioplasty surgery.

\section{References}

[1] Emmens W.C., Sebastiani G., van den Booggard A.H, The technology of Incremental Sheet Forming - A brief review of the history, Journal of Materials Processing Technology, 210, 981-997, 2010.

[2] Park J.-J., Kim Y.-H., Fundamental studies on the incremental sheet metal forming technique, Journal of Materials Processing Technology, 140, 447-453, 2003

[3] Kopac J., Kampus Z., Incremental sheet metal forming on CNC milling machine-tool, Journal of Materials Processing Technology, 162-163, 622-628, 2005 .

[4] Araghi B.T., Manco G.L., Bambach M., Hirt G., Investigation into a new hybrid forming process: Incremental sheet forming combined with stretch forming, Manufacturing Technology, 58, 225-228, 2009.

[5] Kim T.J, Yang D.Y, Improvement of formability for the incremental sheet metal forming process, Inter- 
national Journal of Mechanical Sciences, 42, 12711286, 2000.

[6] Shim M.-S., Park J.-J., The formability of aluminium sheet in incremental forming, Journal of Materials Processing Technology, 113, 654-658, 2001.

[7] Ambrogio G., De Napoli L., Filice L., et. al., Application of Incremental Forming process for high customised medical product manufacturing, Journal of Materials Processing Technology, 162-163, 156-162, 2005.

[8] Petek A., Kuzman K., Kopac J., Deformations and forces analysis of single point incremental sheet met- al forming, Archives of Materials Science and Engineering, 35, 2, 107-116, 2009.

[9] http://www.ennex.com/ fabbers/StL.asp

[10] Karbowski K., Edge detection in reverse engineering system, Advances in manufacturing science and technology, 34, 4, 63-72, 2010.

[11] http://codubix.com/characteristics-of-codubixand-codubix-3d/

[12] Karbowski K., Moskała M., Polak J., Sujka W., Urbanik A., The application of computed tomography to develop a Codubix ${ }^{\circledR}$ prosthesis upon patient's individual request, Acta Clinica et Morphologica, 2, 10-16, 2012. 